\title{
PROBLEMATIZAÇÕES ACERCA DA IMAGEM ENQUANTO CONHECIMENTO DA NATUREZA
}

\section{PROBLEMATIZATIONS ABOUT THE IMAGE AS KNOWLEDGE OF NATURE}

\author{
Hugo Fortes \\ (Escola de Comunicações e Artes - Universidade de São Paulo) \\ hugofortes@usp.br
}

Recibido: 06/05/2018

Aprobado: 11/07/2018

\begin{abstract}
RESUMO
Este artigo investiga as maneiras como a imagem foi compreendida como forma de conhecimento do mundo natural ao longo da história da arte. Inicialmente são apresentados os conceitos de mimesis, natureza naturante, natureza naturada. São discutidas as relações entre natureza e cultura e a ideia da imagem como representação fidedigna do mundo em contraposição à expressão emocional do artista. Também são apresentadas as modificações nos regimes imagéticos com o surgimento da fotografia, do cinema e da imagem eletrônica. Ao final, destacam-se as alterações visuais provocadas pelo homem na paisagem, discutindo o papel da arte no debate ecológico contemporâneo.
\end{abstract}

Palavras-chaves: imagem, natureza, conhecimento

\section{ABSTRACT}

This paper investigates how the image was conceived as a form of knowledge of the natural world throughout art history. Initially, the concepts of mimesis, natura naturans, natura naturata, among others, are presented. The relationship between nature and culture and the idea of the image as a reliable representation of the world as opposed to the emotional, artistic expression are discussed. Modifications on the visuality regimes with the emergence of photography, cinema, and electronic image are also presented. Finally, the visual changes caused by man in the landscape are focused, discussing the role of art in the contemporary ecological debate.

Keywords: image, nature, knowledge

A representação da natureza através de imagens está na origem do próprio surgimento da cultura humana. Desde os primórdios, o homem se debate entre louvar e imitar a natureza ou dominá-la e sobrepor-se a ela. Se, por um lado, o ambiente natural se apresenta como um lugar aprazível, que provê alimento, água e um espaço para o homem habitar, além de ser um repositório dos mitos da criação, por outro lado, também representa ameaças e dificuldades, lançando desafios para a sobrevivência humana. O homem inicia sua trajetória artística ora imitando a natureza para tentar se aproximar dela, ora procurando dominá-la, produzindo objetos que pretendem ser mais perfeitos do que ela. Ao mesmo tempo em que retrata o mundo com suas produções imagéticas, o homem também interfere no mundo, 
alterando sua visualidade. As primeiras imagens produzidas por humanos são pinturas rupestres que inauguram uma discussão se seu caráter seria simbólico e ritual ou se seu objetivo seria a pura representação fidedigna do mundo, afirmando a presença do homem que as produziu e servindo como comunicação entre seus semelhantes. Entre essas imagens, encontramos tanto algumas de caráter mais indicial, nas quais o homem deixa seu rastro soprando pós coloridos sobre sua mão, como aquelas mais simbólicas e esquemáticas que retratam animais e seres humanos.

As primeiras constatações filosóficas mais aprofundadas sobre a imagem enquanto conhecimento da natureza surgem de forma mais consistente no pensamento de Platão. Para ele, o mundo natural, a physis, era apenas uma cópia imperfeita do mundo superior das ideias. O mundo físico em que vivemos já era, por si só, uma imagem ou sombra de uma realidade metafísica inalcançável e a tarefa da filosofia seria, através da razão, eliminar as brumas que enganam os nossos sentidos. O conhecimento deveria se basear no exercício do pensamento racional abstrato, sem se deixar levar pelas aparências enganadoras do mundo. As imagens produzidas pelos artistas eram, para Platão, uma cópia de segunda mão desta cópia imperfeita que é o mundo, e assim só buscavam iludir nossos sentidos e nos afastar da verdade. A imagem não se prestaria ao conhecimento do mundo, que só poderia ser alcançado através do pensamento filosófico e da palavra.

Quando falamos em representação imagética do mundo natural, não podemos deixar de mencionar o conceito de mimesis. Este conceito pode ser tomado em duas acepções diferentes. Uma seria a do fato dos artistas imitarem a aparência dos objetos do mundo natural. Esta acepção é provavelmente a mais conhecida e marcou definitivamente a história da arte, levando ao paradigma que o grande artista é aquele que consegue retratar o mundo da maneira mais fiel e verdadeira. Tal paradigma, entretanto, é questionado em diversos momentos da história das imagens, como veremos adiante. Uma segunda concepção da atividade mimética seria a de que o artista não imita apenas a aparência do natureza, mas, sim, a sua própria força criadora. Assim como a natureza produz incessantemente os seres do mundo, o homem produziria seus objetos povoando o ambiente de artefatos humanos. Desta maneira, o homem produz não só imagens sobre o mundo, mas altera a própria forma como o mundo se apresenta para nossos olhos.

A estas questões somam-se, também, os conceitos de natureza naturante e natureza naturada. A natureza naturada seria o mundo natural visto como acabado, com seu ambiente, animais, vegetais e minerais prontos para oferecerem um lugar de morada para o homem e para serem imitados por sua arte. A natureza naturante refere-se ao princípio criador da natureza, em seu poder de transformação e criação da vida. O conceito de natureza naturante possui um caráter dinâmico, que remete ao fluxo vital que se desenrola no tempo. Diante da constatação do aspecto fluido e mutante da natureza colocam-se várias questões sobre o uso das imagens para o conhecimento do mundo natural e sobre o papel do artista. Como retratar através da imagem estática um devir em transformação constante? Seria a imagem capaz de suspender o tempo, fixando visões ideais para a eternidade? Ou deveria o artista captar a essência do movimento vital sem congelá-lo, deixando-o latente e pulsante mesmo em sua representação estática? Falharia o artista ao tentar retratar em imagens paradas o mundo em transformação constante? Seria, então, a sua cópia do mundo ainda mais imperfeita por não incluir o tempo?

Diferentemente de Platão, Plotino considera que a atividade do artista não é apenas uma imitação da imperfeição, mas é o artista que possibilita que as formas perfeitas penetrem na matéria informe do mundo. Para ele, "a pedra da estátua é bela, não porque é pedra, mas porque o artista inspirado fez com que nela penetrasse uma forma e um brilho que ela não tinha.” (como citado em Ribon, 1991, p. 23). Aristóteles também ressalta que a habilidade de imitar possui em si um valor, já que podemos nos comprazer com o virtuosismo que um artista consegue copiar até mesmo as coisas que não consideramos belas. As imagens poderiam, então, através da harmonia de suas formas, superar o próprio mundo, já que sua beleza poderia nos elevar a mundos metafísicos, distantes da precariedade mundana da matéria. A ideia da superioridade das formas em relação à matéria atravessa toda a Idade Média, chegando até o Renascimento. 
Durante o Renascimento, torna-se cada vez mais importante estudar a natureza com precisão, pois só assim o homem poderia fazer penetrar o belo ideal em suas representações. Artistas como Leonardo da Vinci (1452-1519) e Michelangelo (1475-1564) vão se confrontar com a matéria para extrair dela suas formas perfeitas, porém prezando o conhecimento dos detalhes do mundo natural, que é visto como a medida de todas as coisas. Matéria e espírito entram em confronto e a objetividade de representação é necessária para se atingir a elevação metafísica. A questão do tempo e da fugacidade da natureza naturante é também discutida pelos artistas renascentistas no que diz respeito às diferenças entre a pintura e a escultura. Para Leonardo, a pintura teria maior capacidade de expressar o movimento, os estados fluidos e as condições atmosféricas, por alcançar um grau de abstração maior que a escultura e incluir as nuances de cor e a transparência. Ainda que a concepção renascentista considere importante o estudo da natureza para atingir a representação fidedigna, o mundo natural, entretanto, ainda não é o protagonista das imagens pictóricas do Renascimento, cuja temática central refere-se a Deus, aos santos e ao próprio homem. A natureza apresenta-se mais como pano de fundo para o desenrolar da vida das personagens, e as plantas, animais ou minerais são apresentados como símbolos que remetem a conotações religiosas.

A natureza em si só vai ganhar destaque como tema principal da representação artística a partir da pintura holandesa do século XVII, que inaugura os gêneros da paisagem e da natureza morta. Há uma busca pela objetividade na fatura pictórica holandesa, que embora concentre-se nas aparências do mundo, também pode ser vista como representação simbólica de conteúdos espirituais. Assim, o amplo céu de suas paisagens é compreendido como uma afirmação da presença divina, em contraste com os detalhes da vida mundana que se desenrola sobre a terra. A pintura de paisagem passa a constituir um vocabulário próprio e começa a determinar os modos de ver dos artistas que se sucedem. São ensinados métodos de composição de imagem, formas de enquadramento das visões do mundo natural e estratégias de perspectiva. A perspectiva, aliás, em desenvolvimento desde o princípio do Renascimento, estrutura-se como um modo de conhecimento do visível e permite a tradução da tridimensionalidade do mundo para a planaridade da tela. A imagem, embora busque refletir de modo fiel o mundo, necessita separar-se dele, através do enquadramento circunscrito pela moldura. Os esquemas geométricos de constituição da perspectiva passam a influenciar a própria imagem do mundo real, influenciando no traçado nas cidades e na arquitetura e criando pontos de vista privilegiados para se observar a vida urbana.

Se tomarmos a pintura de paisagem como forma de conhecimento da natureza é necessário esclarecer que o conceito de paisagem não equivale totalmente àquilo que entendemos por natureza. A paisagem, conforme demonstrou Anne Cauquelin (2007) é na verdade o análogon da natureza, isto é, uma construção conceitual humana que busca ser o equivalente da natureza, porém que se dá prioritariamente enquanto imagem. A autora nos informa que nossa percepção atual de paisagem é influenciada pela forma com que a natureza foi representada pela arte ao longo do tempo e é através destes modelos cognitivos incutidos em nosso imaginário que podemos percebê-la. A paisagem, para Cauquelin, está relacionada a uma noção de composição, de ponto de observação e de enquadramento. Há todo um vocabulário da paisagem formado por elementos que conjugados contribuem para a constituição da imagem, que não é o mundo natural propriamente dito, mas um recorte dele. Mesmo quando interfere sobre o mundo real, através do paisagismo, o homem ora busca uma paisagem mais próxima do que seria o natural idealizado, ora assume propositalmente a artificialidade de sua criação.

A representação da natureza através das imagens não se restringe à pintura de paisagem, mas também merece destaque na pintura de natureza morta. A vida silenciosa das naturezas mortas, em que frutas e flores são representadas em seu esplendor e efemeridade, é símbolo para a vacuidade da vida humana. As naturezas mortas reúnem não apenas objetos do mundo natural, mas também artefatos humanos em representações precisas e ao mesmo tempo metafóricas. Os holandeses, como mercadores viajantes, tomam contato com outras culturas, colecionando e comercializando seus objetos. Das coleções particulares, que reuniam nos gabinetes de curiosidades espécimes exóticos e artefatos culturais trazidos de longe, surgem os primeiros museus. As viagens tornam-se importantes instrumentos para o conhecimento, trazendo objetos a serem retratados por artistas ou levando os artistas para tomar contato com novas realidades. Mesmo quando não era possível ir para tão longe, a prática da viagem poderia 
ocorrer dentro do próprio continente europeu, fazendo com que os artistas se deslocassem para os centros de excelência do conhecimento. Albrecht Dürer (1471-1528), por exemplo, ainda entre 1495 e 1505, faz viagens à Itália que são definitivas para trazer os conhecimentos do Renascimento Italiano para o ambiente germânico. O próprio Dürer produziu sua famosa gravura do Rinoceronte sem nunca ter visto o animal, imaginando-o apenas a partir de relatos de um viajante português que o havia visto ao vivo em suas expedições à África. Embora a imagem do rinoceronte não corresponda totalmente à representação do animal, aproxima-se bastante da realidade. Ao mesmo tempo em que cria esta espécie de fantasia de um animal existente, mas que para a sociedade da época toma quase o status de um documento representacional de um animal que eles desconheciam, Dürer também é conhecido por sua capacidade de retratar com muita precisão o mundo natural como ele se apresenta, como é o caso de suas representações de uma lebre ou das magníficas asas de uma arara. Esta dupla possibilidade que a arte oferece, de representar o mundo natural com objetividade, servindo como documento, e ao mesmo tempo poder criar novos mundos, projetando a subjetividade do artista, é uma das questões fundamentais para discorrermos sobre as imagens da natureza.

Objetividade e subjetividade são questões de interesse também quando pensamos no trabalho dos artistas viajantes que acompanhavam as expedições científicas aos novos continentes, que se intensificam sobretudo a partir dos séculos XVIII e XIX. Ao mesmo tempo em que documentavam a flora e a fauna dos novos ambientes que visitavam, muitos dos artistas naturalistas também imaginavam seres inexistentes, quer seja por não se lembrarem exatamente de como eram os animais que tinham visto, quer seja para incrementar suas narrativas de viagens. De qualquer forma, mesmo que não fossem totalmente verdadeiras, suas imagens assumiam o papel de documentos diante dos olhos dos europeus. A questão da documentação visual que a arte proporcionava para a ciência era tão séria que o próprio Alexander von Humboldt (1769-1859) escreveu recomendações para os pintores de paisagem, indicando as melhores formas de se representar a natureza. Também é conhecido o debate que Goethe (1749-1832) teria tido com Caspar David Friedrich (1774-1840), pois o primeiro acreditava que as nuvens deveriam ser pintadas a partir dos critérios científicos estabelecidos pelo meteorologista Luke Howard (17721864), enquanto que o segundo defendia que podia representá-las conforme suas emoções.

As imagens dos novos continentes produzidas por artistas viajantes e multiplicadas através de gravuras e publicações de livros têm papel fundamental no desenvolvimento da ciência. A ilustração naturalista serve não apenas para documentar o mundo visível da fauna e da flora, mas para estudá-lo de forma analítica e racional. A imagem torna-se um importante instrumento para o conhecimento científico e para sua divulgação. Mesmo depois do surgimento da fotografia, a ilustração naturalista persiste devido à sua capacidade analítica em isolar aquilo que interessa do mundo visível. Juntamente a isso, o desenvolvimento da cartografia oferece novas formas de ver o mundo, que não é mais apenas documentado em suas aparências miméticas, mas pode ser representado a partir de modelos e abstrações diagramáticas, que se apresentam como novas formas do conhecimento. As imagens podem servir como guias para navegar o mundo. Não são simplesmente seu espelhamento, mas indicam caminhos para a atuação interveniente do homem. Vilém Flusser (2007) já nos advertiu que ao compreender o território através de mapas, nossa tendência é inverter a relação entre a natureza e sua representação, buscando no espaço do mundo suas correspondências para validar os mapas, esquecendo-nos de que o mapa é a representação da natureza e não o contrário. (Flusser, 2001, p.31). Assim como os mapas, as imagens de um determinado local podem ser tomadas como o local em si, embora nunca correspondam totalmente àquilo que representam. A produção cultural e imagética a respeito da paisagem, ainda que encontre um lastro no mundo natural, distancia-se dele, ao mesmo tempo em que o recria. O pensamento racional e científico produz modelos que tanto retratam o mundo como também se afastam dele.

Ao mesmo tempo em que a arte se aproxima da ciência, produzindo imagens documentais do mundo natural, seu papel como espaço para especulações metafísicas e espirituais não perde totalmente o sentido. A espiritualidade, entretanto, deixa de ser representada puramente através de imagens religiosas, mas passa a ser projetada simbolicamente na poderosa força da natureza. A grandeza das paisagens, a imensidão do mar, a aterradora beleza das montanhas nevadas, a força das cataratas, o mergulho em um mundo tomado por brumas e se abrindo para despenhadeiros são representações do Sublime, que 
dominam a arte romântica. O homem se sente diminuto diante de um poder natural tão arrebatador, que ao mesmo tempo o seduz e o amedronta. O século XIX é marcado por dois movimentos: de um lado o espírito romântico que se entorpece com os mistérios do mundo; do outro, o pensamento neoclássico, que se nutre da razão e da ciência para desvendar esses mistérios. O espírito romântico irá dar origem aos movimentos simbolistas, expressionistas e impressionistas, indo desembocar no surrealismo, já no século XX. A natureza surreal já não necessita de uma conexão mimética com o mundo natural, que é mencionado como símbolo para representar as pulsões do inconsciente. Os mitos que a natureza representa voltam a surgir de maneira transformada, reinventados pela livre-associação do pensamento e pela imaginação. A imagem surrealista é um campo aberto para a experimentação e permite que o conhecimento alcance os mistérios dos pensamentos e das emoções.

A imagem do mundo no início do século XX já não pode mais se desconectar dos avanços da ciência e do sistema de produção capitalista. O olhar ingênuo sobre o mundo natural cede lugar à visões afetadas pelo conhecimento científico e pela vida urbana. Zygmunt Bauman (1998) comenta o reflexo destas alterações do mundo nas visões dos artistas modernos:

\footnotetext{
Muitos deles receberam sugestões e ânimo (...) da ciência e da tecnologia, os mais desafiadores, aventurosos e irreverentes entre as tropas de assalto do moderno despedaçamento da tradição: impressionistas da ótica antinewtoniana, cubistas da anticartesiana teoria da relatividade, surrealistas da psicanálise, futuristas dos motores de combustão e das linhas de montagem. (Bauman, 2008, p. 24)
}

O interesse pela máquina, pelo progresso e pela ciência e o desapego da vida espiritual marcam a vida de um homem cada vez mais urbano que acredita na construção de uma modernidade utópica, em que o humano domina e se sobrepõe à natureza através da tecnociência capitalista. A arte volta-se para a discussão de suas questões internas como linguagem, não apresentando tanto interesse em retratar o mundo natural. A ciência impõe-se definitivamente, junto da produção em massa e o desenvolvimento dos meios de comunicação. Ciência e arte passam a se distanciar cada vez mais, sendo que a primeira volta-se para a constituição de modelos abstratos e para a análise do mundo em sua microcomposição atômica ou em seu macrocosmo inalcançável, enquanto que a arte se preocupa com a expressividade ou com a afirmação de sua autonomia enquanto linguagem, refutando a ideia da imitação mimética do mundo.

As representações visuais da natureza variam de acordo com as possibilidades tecnológicas e científicas da época em que são produzidas. Enquanto no século XVIII, a ilustração pictórica é uma das únicas possibilidades de representação visual da natureza, quer seja com objetivos científicos ou artísticos, a introdução da fotografia no final do século XIX e o posterior surgimento dos métodos eletrônicos de captação de imagens em meados do século XX geraram profundas alterações em nossa capacidade de representar e perceber o mundo visível. Sobre a transição da pintura para a fotografia, Walter Benjamin (como citado em Di Felice, p. 2009) nos fala da "passagem da mão para o olho", remetendo à mudança epistemológica que ocorre entre a representação essencialmente simbólica da pintura e o caráter mais indicial da fotografia. A fotografia passa a oferecer a almejada objetividade buscada pelo conhecimento científico e em seu princípio é vista como um retrato fiel do mundo natural. Esta nova forma de se conhecer o mundo a partir das imagens é descrita por Henry Fox Talbot (1800-1877) como o "pincel da natureza", dada a precisão com que capta os reflexos do mundo.

Se em seu princípio a fotografia ainda não é totalmente considerada arte, pouco a pouco se reconhecem os procedimentos subjetivos e as possibilidades estilísticas presentes em sua linguagem. Ao mesmo tempo, as conquistas permitidas pela fotografia oferecem aos pintores novas formas de ver o mundo, que passam a incorporar artifícios da linguagem fotográfica em suas composições e chegam até a usar projeções de imagens para produzir imagens hiper-realistas. O desenvolvimento da fotografia microscópica, da fotografia aérea e da possibilidade de captação de imagens do espaço sideral dão origem a novas imagens de coisas nunca antes vistas a olho nu.

Além da fotografia, o cinema também oferece novas formas de ver o mundo. A antiga dificuldade de retratar a natureza naturante em sua transformação constante através de imagens estáticas é agora 
superada pelo surgimento das imagens em movimento. O tempo pode ser analisado, simulado, acelerado, ralentado ou até mesmo invertido na linguagem cinematográfica. A imagem, conjugada com o tempo, pode agora oferecer narrativas do espaço do mundo, conjugando-se à linguagem verbal e sonora. A natureza é um tema de grande interesse desde os primórdios do cinema. Ainda no final século XIX, Etienne Jules Marey (1830-1904) já observava o movimento de seres aquáticos em um aquário através de uma técnica precursora do cinema, chamada cronofotografia. (Fortes, 2012). São bastante conhecidos, também, os estudos fotográficos de movimento, não só de humanos, mas também de animais, realizados por Edward Muybridge (1830-1904). Os irmãos Lumière (Auguste: 1862-1954 Louis: 1864-1948), em seus primeiros filmes, também se interessavam pelo movimento de peixes e animais. A natureza destacase como tema para produções cinematográficas que, ao mesmo tempo em que permitem a observação científica, funcionam como interessante entretenimento. Os filmes de Jean Painlevé (1902-1989), produzidos nas primeiras décadas do século XX, apresentam novos olhares sobre a natureza, conjugando a observação científica de seres do mundo natural com narrativas envolventes e até mesmo fantasiosas. O cinema documental mescla-se à ficção científica, produzindo imagens híbridas que oscilam entre a objetividade e o entretenimento. O conhecimento presente nestas imagens não deve ser apenas racional, mas seduzir o espectador e popularizar os conteúdos da ciência. Até hoje, as produções visuais deste tipo nos encantam, desde os filmes de Jacques Cousteau (1910-1997), nos anos 60, até as recentes reportagens sobre o mundo natural feitos pela National Geographic e BBC News, entre outras.

Há, entretanto, diferenças no modo de constituição das imagens pictórica, fotográfica, cinematográfica e eletrônica. A imagem pictórica dá-se a partir da livre interpretação estética do mundo pelo artista e depende da sua habilidade manual para se constituir. Já as imagens fotográficas e cinematográficas analógicas, ainda que também contenham traços de subjetividade através dos processos de enquadramento e edição, dependem da impregnação da luz refletida nos objetos do mundo. Elas se condensam em um suporte fílmico sensível a luz. Já as imagens de origem eletrônica, como o vídeo e a fotografia digital, surgem pela tradução dos impulsos luminosos em códigos manipuláveis e que podem ser transmitidas em diferentes formatos, resoluções e equipamentos.

Para Massimo di Felice (2009), a imagem da pintura seria uma imagem de primeira geração, a da fotografia e do cinema, de segunda geração e a dos meios eletrônicos, de terceira geração. Massimo di Felice comenta ainda sobre as imagens de terceira geração, produzidas pelos meios eletrônicos:

\begin{abstract}
Se tal transformação tecnológica da imagem, como na nova visão de universo elaborada pelo olho mecânico de Galileu, modifica a natureza e sua própria percepção, a introdução da imagem eletrônica, da imagem pixel e da imagem de síntese impõe dinamismos ulteriores e o surgimento de outros tipos de deslocação. Existe um consenso muito difundido entre os especialistas da mídia eletrônica de que o tipo de imagem produzida pelas novas tecnologias - a "info-imagem” ou as "imagens de síntese”- provocaria uma ruptura com aquelas produzidas pela pintura, pelo foto e pelo cinema, enquanto imagens virtuais, "auto-referentes" e autônomas. De fato, se a pintura, a foto e o cinema pressupõem o real, as imagens de terceira geração rompem com os modelos de representação, sendo elas mesmas simulações. (Di Felice, 2009, p. 209).
\end{abstract}

A percepção das imagens eletrônicas como realidades autônomas e passíveis de alteração torna-se, hoje, ainda mais presente, já que os processos de manipulação de imagens estão cada vez mais acessíveis em nossos computadores pessoais. A imagem já não é mais um documento representativo da realidade, mas uma configuração instável, que pode ou não encontrar um referente no mundo sensível. A ausência de um suporte material, sobre o qual as imagens fixam-se, podendo funcionar como documento da verdade, leva a uma insegurança sobre o potencial de espelhamento do mundo. O surgimento e popularização das câmeras digitais, dos computadores, das câmeras de celulares, da Internet e das redes sociais tornou possível a qualquer pessoa produzir suas imagens e as manipular. A instabilidade da imagem enquanto documento na contemporaneidade é percebida de maneira cada vez mais consciente, já que nos acostumamos a visualizar notícias falsas que se apoiam no poder narrativo das imagens para se afirmar como verdadeiras.

Além disso, o modo compositivo das imagens também se altera e hoje há pouca diferença entre o que chamamos de ilustração artística e imagem fotográfica. Os artistas e designers contemporâneos podem mesclar em seus trabalhos todos os sistemas imagéticos das épocas anteriores, misturando o desenho, a 
pintura, a colagem, a fotografia, o cinema, e as imagens digitais de todo tipo. A sobreposição de telas a que estamos acostumados em nossos computadores e celulares também gera novas formas de composição, que incluem a transparência, a sobreposição, o movimento e a existência de espaços virtuais. Afora isso, dispomos das mais variadas tecnologias visuais, desde as imagens 3D até as animações computadorizadas, as "caves" de imersão em realidade virtual, as holografias, as imagens em realidade aumentada e ainda veremos surgir inúmeras outras tecnologias da imagem. Todos esses regimes imagéticos podem conviver em um único espaço e serem visualizados ao mesmo tempo. A facilidade da realização de projeções digitais no espaço tridimensional do mundo, através das mais avançadas técnicas de videomapping ou mesmo através de simples projeções, altera a visualidade do espaço que habitamos. Além disso, a presença massiva de telas digitais em todos os locais que circulamos, também modifica nossa percepção do entorno e nos permite a visualização simultânea de diferentes realidades. Mesmo se nos deslocarmos a um ambiente natural distante, buscando um maior contato com a natureza, estaremos provavelmente munidos de nossos aparelhos celulares e poderemos, através deles, tanto produzir imagens daquilo que vemos, alterá-las e transmiti-las em tempo real, como também poderemos ver imagens de outros lugares e tempos, estabelecendo assim simultaneidades temporais e espaciais.

As imagens eletrônicas da natureza e da paisagem podem ainda se apresentarem distantes do que realmente experimentamos no mundo sensível, mostrando-se, às vezes, até mais belas do que a natureza real. Para Anne Cauquelin (2007),

\footnotetext{
a paisagem, com a imagem digital (...) é uma pura construção, uma realidade inteira, sem divisão, sem dupla face, exatamente aquilo que ela é: um cálculo mental cujo resultado em imagem pode - mas isso não é obrigatório - assemelhar-se a uma das paisagens representadas existentes. (Cauquelin, 2007, p. 180)
}

Desta maneira, as paisagens digitais influem em nossa percepção do mundo natural e criam outras naturezas possíveis no espaço virtual. A mediação que as imagens nos impõem nos impossibilitam de estabelecer uma relação de intimidade sensível com o mundo, mesmo que elas nos permitam vê-lo em seus mínimos detalhes. Além disso, não foram apenas as imagens que se modificaram, mas a própria visualidade do mundo alterou-se, devido à intervenção humana. A natureza já não é mais o que foi para as gerações passadas e o impacto do homem sobre o ambiente é incomensurável. No mundo contemporâneo, já não mais conseguimos pensar em uma natureza idílica, intocável, como uma espécie de refúgio paradisíaco. Nossas paisagens receberam ao longo dos séculos muitas intervenções humanas, que alteraram suas constituições, estabeleceram fronteiras inexistentes, modificaram seu solo pela indústria agrícola, desviaram o curso de rios, interferiram no crescimento de animais e vegetais, criaram seres transgênicos, provocaram chuvas artificias, contribuíram para o desmatamento e a extinção das espécies, produziram animais em série e alteraram o ambiente de todas as maneiras. O homem urbano vive cada vez mais longe do mundo natural, tendo contato com ele às vezes, apenas através de imagens, quase sempre, digitais. A divulgação científica, popular como entretenimento nos meios de comunicação, permite-nos saber vários detalhes da biologia de um animal, até mesmo sua composição celular e genética, mesmo que nunca o tenhamos visto de perto. O conhecimento sensível no contato direto com o ambiente natural é substituído pela compreensão de modelos abstratos e codificados. Os simulacros estão por todos os lados e tomam o lugar das coisas. As imagens misturam-se à tridimensionalidade do mundo, criando paisagens interativas que reúnem o perto e o distante, o real e o virtual, a natureza e a cultura em híbridos indistinguíveis.

Muitos filósofos contemporâneos questionam a possibilidade de se fazer uma distinção entre natureza e cultura na sociedade contemporânea. Vilém Flusser (2011), por exemplo, parece afirmar uma impossibilidade de acessarmos a natureza como coisas em si, já que nos relacionamos com ela apenas através dos modelos mentais que aprendemos em nossa cultura. Donna Haraway (2008) substitui as palavras cultura e natureza pelo neologismo naturezacultura. Apenas através da compreensão desta nova realidade complexa e do nível de atuação do homem sobre o mundo natural é que poderemos tomar atitudes sustentáveis para a perpetuação sustentável de nossa espécie e dos seres que nos acompanham no ambiente em que vivemos. Pensar em naturezacultura é assumir a responsabilidade do homem sobre o mundo que o cerca. O conhecimento que buscava encontrar a verdade do mundo, separando o referente 
real da representação que enganava os sentidos, ou seja, separando o mundo natural das imagens que o refletem, parece encontrar pouco espaço no mundo contemporâneo. Nesta profusão de imagens em que vivemos, reais ou virtuais, naturais ou digitais, só nos resta investigar e dominar os códigos de produção visual e usá-los de modo efetivo em nossa atuação sobre o mundo.

Há muito tempo que a produção de imagens deixou de ser privilégio dos artistas. Além de recebermos uma grande quantidade de imagens da ciência e das mídias comunicacionais, também podemos produzir nossas próprias imagens e transmiti-las facilmente. Porém, a característica indagadora da arte, que se autoquestiona constantemente enquanto produtora de imagens do mundo, pode contribuir para que tenhamos um olhar mais consciente da natureza, ou ao menos do que resta dela. O artista contemporâneo vê-se diante deste panorama complexo e deve responder a ele. Estão à sua disposição camadas de história com um longo passado iconográfico, imagens e conceitos da ciência e da cultura midiática e possibilidades expressivas as mais diversas, nos mais variados suportes. Cada artista encontra seu meio de reagir a isso e é sua singularidade que garante que vivamos em um espaço-tempo marcado pela diversidade e pela instabilidade.

A preocupação com a natureza é apenas um tema entre muitos outros na produção artística contemporânea e se apresenta misturada a diversos outros assuntos na poética de cada artista. Há desde artistas que se envolvem consequentemente com o engajamento ecológico, até aqueles que criam mundos virtuais nos quais seres eletrônicos desenvolvem-se a partir de códigos genéticos. Há artistas que buscam o sublime através da artificialidade de mundos construídos e há aqueles que estabelecem diálogos com os estilos históricos da paisagem e da natureza morta. Há os que criticam a ciência, demonstrando a subjetividade contida na organização dos museus de história natural e há os que utilizam as próprias conquistas científicas para criar seres transgênicos e híbridos como forma de arte. Há os que salientam nosso afastamento da natureza, através da exacerbação da artificialidade, e há os que desenvolvem trabalhos com materiais ecológicos, preocupados com o impacto sobre o meio ambiente. Há os que denunciam as relações capitalistas de submissão presentes no manejo do mundo natural e há os que buscam na natureza um refúgio para suas questões existenciais. E há, sobretudo, os que trafegam entre todas essas posturas e reinventam o seu estar no mundo a partir de seu trabalho.

Proporcionar a escuta admirativa da natureza é, sem dúvida, um dos papéis que a arte pode assumir neste panorama complexo. É elevando a consciência sobre o mundo natural que ela pode contribuir para tomarmos atitudes mais sustentáveis. Ética e estética podem se aproximar para promover o respeito ao ambiente natural e sua contemplação. Não se trata de impor uma agenda à criação artística, exigindo que ela resolva todos os problemas humanos ou tenha que ser necessariamente engajada ecologicamente. Há várias maneiras da arte atuar politicamente, desde a movimentação social ativista até a pura sensibilização de um único indivíduo que pode contemplar uma obra artística por alguns minutos e repensar sua postura diante do mundo natural. A arte não necessita ser uma intervenção direta e racionalista sobre o ambiente que nos cerca. O fundamental é que ela nos sensibilize para a tomada de consciência. Não é apenas através da sugestão de medidas drásticas e panfletárias que o artista pode afetar seu público a respeito de questões ecológicas. Resgatando o conteúdo espiritual e mítico que a natureza representa, o trabalho artístico também pode instigar o respeito a nosso ambiente e fazer nos reconhecermos como seres que fazem parte deste complexo coletivo.

Para alcançar isso, não basta que a arte simplesmente mencione questões ecológicas, sendo utilizada de modo instrumental para ilustrar conceitos de outras áreas. A arte existe como discussão de linguagem em si e é a partir da elaboração criativa de seus conceitos e conteúdos formais que ela pode arrebatar mais profundamente seu público. É necessário que haja uma compreensão por parte da ciência, da política e de todas as áreas do conhecimento com as quais a arte pode efetivamente contribuir para pensar a condição humana no ambiente terrestre. Mesmo em um mundo totalmente artificializado e povoado por camadas de imagens instáveis que nos seduzem ao mesmo tempo que nos confundem, pode a arte funcionar como uma forma de conhecimento e atuação efetiva sobre o mundo. A natureza, mesmo que ameaçada, é nossa morada e o que garante nossa sobrevivência. Saber olhar para ela, sem se apegar a cânones, técnicas ou tecnologias, mas utilizando as imagens de forma consciente e investigadora em 
todas as suas potencialidades é fundamental para se pensar o mundo contemporâneo. Muito além de seu caráter puramente representativo, a imagem pode nos proporcionar um olhar afetivo e sobretudo político sobre o mundo natural. Este olhar não é simplesmente passivo e receptor, mas deve atuar construindo novas realidades, enxergando a natureza não como algo distante e inalcançável, mas como o espaço em que vivemos e pelo qual somos responsáveis. Esperamos que a profusão das imagens na vida contemporânea não sirva para nos cegar, mas, sim, para nos fazer ver o que é necessário para a perpetuação da vida.

\section{Referências}

Bauman, Z. (1998). O mal-estar da pós-modernidade. Rio de Janeiro: Jorge Zahar Ed.

Cauquelin, A. (2007). A invenção da paisagem. São Paulo: Martins.

Di Felice, M. (2009). Paisagens Pós-urbanas: o fim da experiência urbana e as formas comunicativas do habitar. São Paulo: Annablume.

Fortes, H F. S, Jr. (2012) Telas líquidas: a água na produção audiovisual. Revista Esferas, 1(1), 19-25.

Flusser, V. (2011). Natural:mente: vários acessos ao significado de natureza. São Paulo: Annablume.

Haraway, D. (2008). When species meet. Minnesota: University of Minnesota Press. 